\title{
Resiliency as a mediator of the impact of sleep on child and adolescent behavior
}

\author{
Alex Chatburn ${ }^{1,2}$ \\ Scott Coussens ${ }^{1,2}$ \\ Mark J Kohler ${ }^{1,3}$ \\ 'School of Psychology, Social Work \\ and Social Policy, University of South \\ Australia, Adelaide, SA, Australia; \\ 2Department of Respiratory and Sleep \\ Medicine, Women's and Children's \\ Health Network, North Adelaide, \\ SA, Australia; ${ }^{3}$ Children's Research \\ Centre, University of Adelaide, \\ Adelaide, SA, Australia
}

This article was published in the following Dove Press journal:

Nature and Science of Sleep

23 December 2013

Number of times this article has been viewed

Background: Disturbed sleep is detrimental to child behavior; however, the precise means by which this association occurs is unclear. Sleep and resilience can theoretically share an underlying neural mechanism and therefore influence one another. However, the role of resilience in the association between sleep and behavior is not known. The associations between sleep, resilience, and problematic behavior in children and adolescents aged 7-18 years were investigated in this study.

Methods: A correlational design was used to determine the relationships between total sleep problems, indices of resilience, and internalizing and externalizing behaviors.

Results: Sleep problems and resiliency variables were strongly correlated, and further, sleep problems were found to be predictive of resiliency scores. Resiliency significantly mediated the relationship between increased sleep problems and both overall internalizing and externalizing behavior problems, and specifically, measures of depression and anxiety.

Conclusion: Sleep impacted levels of resilience such that greater sleep disturbance reduced resilience and consequently increased problematic behavior, potentially predisposing individuals to psychopathology.

Keywords: resilience, behavior, internalizing, externalizing, anxiety, depression, sleep

\section{Introduction}

A recent meta-analysis ${ }^{1}$ points to a causal role of sleep disruption in the development of disturbances to emotional regulation in children, such as disorders of anxiety and depression. Leahy and Gradisar found that although emotional problems do inhibit the capacity of the individual to attain sleep (that is, sleep onset requires feelings of safety and comfort inhibited by the hyper-vigilance of anxiety and the rumination of depression), ${ }^{2,3}$ there is presently more research published in support of the opposite direction of relationship: that sleep problems tend to precede, and may precipitate, emotional problems in children. Support for this idea can be found in several clinical studies (see Gregory and $\mathrm{Sadeh}^{4}$ for a review). These highlight the similarities in the behavioral and emotional effects of sleep loss and lack of resiliency. For instance, sleep disruption has been hypothesized to predispose or precipitate depression..$^{2,5-7}$ Sleep loss has also been implicated in the development of anxiety in both adults ${ }^{8}$ and children, ${ }^{1,9,10}$ as well as in the development of posttraumatic stress disorder in adults ${ }^{11}$ and youths. ${ }^{12}$

Resilience is defined as the ability of the individual to adapt positively to negative situations and recover from environmental stressors, ${ }^{13}$ or more simply, "the ability of individuals to recover functioning after exposure to extreme stress". ${ }^{14}$ Resilience in general, as a dynamic systemic variable comprising neurobiological,

Correspondence: Mark J Kohler School of Psychology, Social Work and Social Policy, University of South Australia, GPO Box 247I, Adelaide, SA 500I, Australia

$\mathrm{Tel}+61883024919$

Fax $+6 I 883024729$

Email mark.kohler@unisa.edu.au 
genetic, and environmental factors, has been proposed to have protective and/or recovery-related functions regarding psychopathology. ${ }^{13,15,16}$ Despite some work linking resilience with resistance to depression in both children and adults ${ }^{17,18}$ there has been little empirical support for specific and measurable effects of resilience in preventing psychopathologies. One potential factor which may well contribute to resilience is a good night's sleep. The similar consequences of sleep loss and reduced resiliency for the emotional functioning of the individual suggests that the concepts are potentially linked both within the physiology of the nervous system and in the behavior of the individual. Recent work looking at related concepts of "mental toughness" and optimism similarly suggest an association with sleep quality. ${ }^{19,20}$

There is increasing evidence for a link between resiliency and sleep in children based on neural factors. Research indicates that sleep loss inhibits the functioning of brain areas vital for resilience. The capacity of the individual child for resilience has been linked with the genetic modulation of prefrontal brain activity. ${ }^{21}$ Similarly, the prefrontal cortex has been implicated in the pathophysiological outcomes of disrupted sleep in children. One model proposes that sleep disruption inhibits sleep-related restorative processes and induces neuro-cellular damage, predominantly in prefrontal regions. ${ }^{22}$ The resulting executive dysfunction inhibits the functional application of cognitive abilities, resulting in maladaptive daytime behaviors. The functioning of several other brain structures and systems, including areas important for autonomic activation (hypothalamus-pituitary-adrenal axis, the noradrenergic system, the serotonergic system, and the dopaminergic system), emotion (hippocampus and amygdala), and interhemispheric information transfer (corpus callosum) have similarly been linked to both resilience and sleep quality in children, ${ }^{21,23-25}$ further suggesting a relationship between sleep and the capacity of the individual to resist psychopathology in relation to stressors.

Sleep and resilience appear to be associated with similar brain areas, and sleep loss and loss of resilience share similar behavioral consequences. This would support recent findings which suggest that sleep loss may serve as a causal factor in the development of childhood anxiety, ${ }^{1}$ and could be generalized to behavioral and emotional problems more generally.

The present study aims to delineate the relationship between sleep, resilience, and behavior in children. It is hypothesized that there will be a relationship between sleep problems and behavioral problems. In addition, there will be an association between increased sleep problems and reduced resiliency in children. We also hypothesize that there will be a relationship between resiliency and behavioral problems, with less resilient children and adolescents exhibiting more problematic behavior. Finally, we hypothesize that resiliency will mediate the relationship between sleep and psychopathology, whereby levels of resilience serve as a mechanism through which sleep problems result in behavioral disturbance.

\section{Method}

\section{Participants}

A total of 61 participants (32 male) took part in this study. Demographic details of the sample are presented in Table 1. Participants were recruited from a community-based participant database that contained details of parents who had indicated their availability to be contacted for research participation, and through referral from other participants. Selected participants and their parents were sent a package containing an information sheet, consent form and questionnaires, as well as a reply-paid envelope. Participants completed the questionnaires at their homes and returned them to the researchers, including a statement of informed consent. All participants included in the study were reported to have no diagnosed psychological or medical conditions which affect sleep, cognitive performance or behavior, did not take medications known to affect neuropsychiatric measures, and spoke English as their primary language. The study was approved by the Women's and Children's Health Network and the University of South Australia Human Research Ethics Committee.

Each participant's socioeconomic status was measured using the Australian Bureau of Statistics' Index of Relative Socio-economic Advantage/Disadvantage 2006 national census data. Higher scores on this measure are indicative of greater amounts of household income and occupation skill

Table I Demographic and performance measures

\begin{tabular}{llll}
\hline & Mean (SD) & Minimum & Maximum \\
\hline Age (years) & II.25 (2.55) & 7.0 & 18.0 \\
School grade & $5.75(2.50)$ & 2nd & 12 th \\
SES & $1,008.45(59.49)$ & 902.0 & $1,111.0$ \\
Anxiety & $40.59(7.98)$ & 31.0 & 65.0 \\
Depression & $41.80(8.28)$ & 34.0 & 73.0 \\
Externalizing behavior & $45.26(9.08)$ & 33.0 & 64.0 \\
Internalizing behavior & $47.69(9.54)$ & 33.0 & 67.0 \\
SDSC total & $48.80(9.68)$ & 28.0 & 82.0 \\
Sense of mastery & $58.38(11.6)$ & 23.0 & 74.0 \\
Sense of relatedness & $57.52(9.77)$ & 27.0 & 68.0 \\
Emotional reactivity & $41.43(9.67)$ & 29.0 & 70.0 \\
Resource index & $58.75(11.39)$ & 22.0 & 73.0 \\
Vulnerability index & $39.87(11.08)$ & 25.0 & 69.0 \\
\hline
\end{tabular}

Abbreviations: SD, standard deviation; SDSC, sleep disorders scale for children; SES, socioeconomic status. 
or training relative to the geographic location. This measure features a national mean of 1000 , and a standard deviation of 100. Using these values as normative, the present sample was considered to be representative of the general population.

\section{Materials}

Resiliency was assessed with child/adolescent self-reports on the Resiliency Scales for Children and Adolescents (RSCA). ${ }^{26}$ The RSCA is a reliable and valid measure of resiliency in children, ${ }^{27,28}$ and is comprised of 64 items which each load onto one of three scales. Sense of mastery measures optimism, self-efficacy, and adaptability; sense of relatedness measures trust, perceived social support, comfort, and tolerance; and emotional reactivity measures sensitivity, recovery, and impairment. Each item has a five-point Likert scale response $(0=$ never, $1=$ rarely, $2=$ sometimes, $3=$ often, and $4=$ almost always) written at a third-grade reading level. ${ }^{29}$ Higher scores on the sense of mastery and sense of relatedness scales are indicative of higher resilience, whereas higher scores on the emotional reactivity scale indicate lower levels of resiliency. Finally, scales are combined to form two indices of resiliency. The resource index (RI), which represents overall resiliency, is derived from the mean of the sense of mastery and sense of relatedness T-scores. The vulnerability index (VI), (which, as opposed to a resistance from threat, represents vulnerability to it), is derived by subtracting the RIT-score from the emotional reactivity T-score. Both RI and VI scores are converted to T-scores based on age. The following descriptors for interpreting the magnitudes of the $\mathrm{T}$ scores are recommended: high ( $\geq 60$ ); above average (56-59); average (46-55); below average (41-45); and low $(\leq 40) .{ }^{26}$ Cronbach's $\alpha$ for the RI and VI are reported as $\geq 0.93$, and test-retest validity for these indices have all been reported as $\geq 0.75$. $^{29,30}$

Sleep and sleep problems were assessed by parents through the Sleep Disturbance Scale for Children (SDSC). ${ }^{31}$ This is a 26-item measure which assesses several indices of sleep disturbance in children, including disorders of initiating and maintaining sleep (eg, sleep latency and duration, night awakenings, reluctance to go to bed), sleep breathing disorders (eg, snoring and sleep apnea), disorders of arousal/nightmares (eg, sleepwalking, nightmares, and night terrors), sleep/wake transition disorders (eg, hypnagogic hallucinations and rhythmic movement disorders), disorders of excessive somnolence (eg, daytime somnolence and tiredness on waking), and sleep hyperhidrosis (eg, night sweating). Indices are combined to form a total SDSC score and corresponding T-score. All items are measured on a five-point Likert scale, in which $1=$ never, $2=$ occasionally, $3=$ sometimes, $4=$ often, and $5=$ always .
The SDSC is reported to have high internal consistency among both healthy $(\alpha=0.79)$ and sleep disordered participants $(\alpha=0.71)$, as well as high test-retest reliability $(r=0.71)$.

Behavioral problems were assessed by parents with the Child Behavior Checklist (CBCL). ${ }^{32}$ The CBCL is composed of 113 questions which are answered by the child's parent or caregiver (on a scale of $0-2$, wherein 0 indicates "never," 1 indicates "sometimes," and 2 indicates "often"), and encompass eight subscales (withdrawn/depressed, anxious/ depressed, somatic complaints, social problems, thought problems, attention problems, rule breaking, and aggressive behavior). These subscales are grouped and summed in order to derive internalizing, externalizing, and total problem scores, and are converted into T-scores in order to enable comparisons. The CBCL has been verified as a valid and robust measure in many cross-cultural studies. ${ }^{32,33}$

Behavioral problems were also assessed by child/adolescent self-reports with the Beck Youth Inventory of Social and Emotional Impairment (BYI). ${ }^{34}$ The BYI is composed of five subscales of 20 questions each, which measure anger, depression, anxiety, disruptive behavior, and self-concept. Participants respond to questions on a four-point Likert scale, with possible answers ranging from 0 (never) to 3 (always). These answers are then summed, giving a potential range of scores from 0 to 60 , with higher scores indicative of better functioning. The BYI has been found to have strong internal, test-retest reliability, and construct validity. ${ }^{35}$

\section{Statistical analysis}

Associations between demographic data and measures of sleep, behavior, and resiliency were analyzed with Pearson's correlations. The relationships between SDSC measured total sleep problems and resiliency measures were analyzed through Spearman's correlations. Bootstrap mediation analyses (using 5,000 samples) were undertaken to examine the effect of sleep problems on anxiety and depression (measured on the BYI) and internalizing and externalizing problems (CBCL), and whether overall resiliency mediated the impact of sleep problems on behavior. Preacher and Hayes's ${ }^{36}$ method was chosen for the analyses, as it reduces the likelihood of Type 1 error while testing for multiple mediators and covariates, and without relying on the assumptions of normal sampling distributions. ${ }^{37,38}$ Significance was determined at $P=0.05$.

\section{Results Demographic analysis}

Correlations between sleep and demographic variables revealed negative relationships between disorders of arousal 
and age ( $r=-0.286, P=0.027, \mathrm{~N}=60)$ and year level at school ( $r=-0.314, P=0.015, \mathrm{~N}=59$ ). No significant relationships were found between demographic factors and psychopathology variables or demographic and resiliency factors.

\section{Correlations}

Results of initial correlational analyses between sleep problems, behavior problems, and resiliency scores indicated a range of correlations in line with our predictions between sleep and resiliency variables. Specifically, negative correlations were found between increased sleep problems and the RI, and positive correlations between increased sleep problems and the VI. Also, greater problematic behavior was significantly associated with increased sleep disturbance and reduced resiliency (or increased vulnerability) across all measures. Results of this analysis are presented in Table 2.

\section{The relationship between sleep, $\mathrm{RI}$, and emotional problems}

The predictive model of problematic behavior was significant in each case, explaining $38 \%, 29 \%, 54 \%$, and $56 \%$ ( $P<0.001$ for each) of the variance in internalizing behaviors, externalizing behaviors, anxiety, and depression, respectively. RI partially mediated the impact of sleep disturbance on each behavior. However, the effect of sleep disturbance on behavior remained significant in each case after the addition of RI to the model.

\section{Total internalizing problems}

The results from the internalizing behavior analysis confirmed a partial mediation model (Figure 1A). That is, the total effect of sleep disturbance on internalizing behavior ( $b=0.52, P<0.001)$ decreased with the inclusion of RI into the

Table 2 Inter-correlations between behavior, sleep, and resiliency variables

\begin{tabular}{llllllll}
\hline & $\mathbf{I}$ & $\mathbf{2}$ & $\mathbf{3}$ & $\mathbf{4}$ & $\mathbf{5}$ & $\mathbf{6}$ & $\mathbf{7}$ \\
\hline $\begin{array}{l}\text { I. Anxiety } \\
\text { 2. Depression }\end{array}$ & - & $0.8 \mathrm{I}^{\mathrm{a}}$ & - & & & & \\
$\begin{array}{l}\text { 3. Externalizing } \\
\text { behavior }\end{array}$ & $0.45^{\mathrm{a}}$ & $0.43^{\mathrm{b}}$ & - & & & \\
$\begin{array}{l}\text { 4. Internalizing } \\
\text { behavior }\end{array}$ & $0.33^{\mathrm{b}}$ & $0.45^{\mathrm{a}}$ & $0.60^{\mathrm{a}}$ & - & & \\
$\begin{array}{l}\text { 5. SDSC total } \\
\text { 6. Resource }\end{array}$ & $0.62^{\mathrm{a}}$ & $0.57^{\mathrm{a}}$ & $0.46^{\mathrm{a}}$ & $0.53^{\mathrm{a}}$ & - & \\
$\quad-0.68^{\mathrm{a}}$ & $-0.72^{\mathrm{a}}$ & $-0.49^{\mathrm{a}}$ & $-0.57^{\mathrm{a}}$ & $-0.56^{\mathrm{a}}$ & - & \\
index & & & & & & & \\
7. Vulnerability & $0.76^{\mathrm{a}}$ & $0.78^{\mathrm{a}}$ & $0.54^{\mathrm{a}}$ & $0.5 \mathrm{I}^{\mathrm{a}}$ & $0.60^{\mathrm{a}}$ & $-0.92^{\mathrm{a}}$ & - \\
index & & & & & & & \\
\hline
\end{tabular}

Notes: ${ }^{\mathrm{a} P}<0.001 ;{ }^{\mathrm{b}} \mathrm{P}<0.005$.

Abbreviation: SDSC, sleep disorders scale for children.

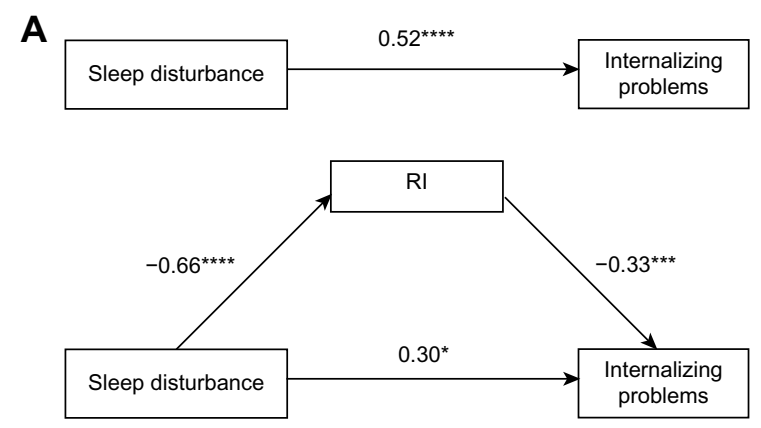

B
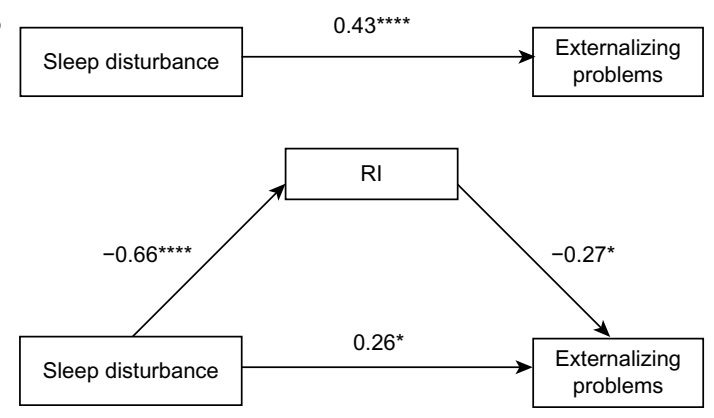

C
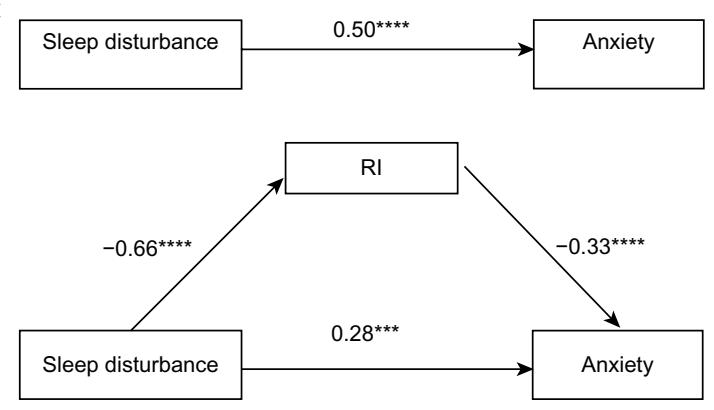

D
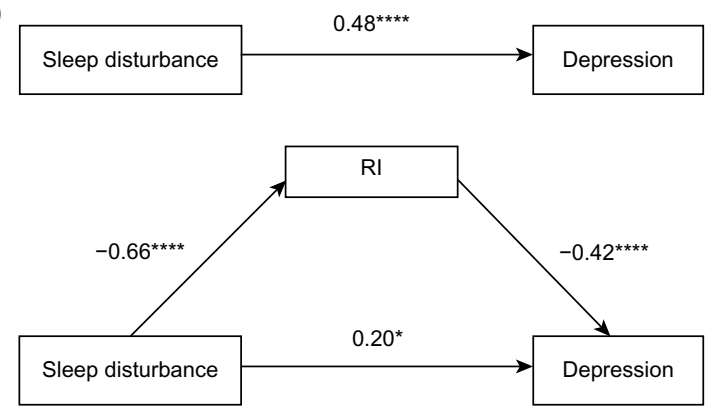

Figure I The effects of sleep disturbance, and mediation by reported resiliency on: (A) total internalizing problems; (B) externalizing problems; (C) anxiety symptoms; and (D) depression symptoms.

Notes: For each panel, the upper box is the association between degree of overall sleep disturbance and the behavioral variable, while the lower panel is the association after resiliency scores were entered into the model as a mediating variable. All numbers represent unstandardized coefficients. Solid lines indicate significant and dashed lines non-significant relationships. $* P<0.05$, $* * * P<0.005$, and $* * * * P<0.001$.

Abbreviation: $\mathrm{Rl}$, resource index. 
model (direct effect $=0.30, P<0.05$ ). The total indirect effect of sleep disturbance through RI on internalizing behavior was significant (point estimate $=0.22,95 \%$ confidence interval [CI] 0.09-0.45, $P<0.01)$.

\section{Total externalizing problems}

The results from the externalizing behavior analysis also revealed partial mediation (Figure 1B). The total effect of sleep disturbance on externalizing behavior $(b=0.43$, $P<0.001)$ decreased with the inclusion of RI into the model (direct effect $=0.26, P<0.05$ ). The total indirect effect of sleep disturbance through RI on externalizing behavior was significant (point estimate $=0.18,95 \%$ CI $0.05-0.38$, $P<0.05)$.

\section{Anxiety}

The results from the anxiety analysis revealed partial mediation (Figure 1C). The total effect of sleep disturbance on reported anxiety $(b=0.50, P<0.001)$ decreased with the inclusion of RI scores into the model (direct effect $=0.28$, $P<0.005$ ), and this change was statistically significant (total indirect effect $=0.22,95 \%$ CI $0.09-0.43, P<0.001$ ).

\section{Depression}

The results from the depression analysis revealed partial mediation (Figure 1D). The total effect of sleep disturbance on reported depression $(b=0.48, P<0.001)$ decreased with the inclusion of RI scores into the model (direct effect $=0.20$, $P<0.05$ ), and this change was statistically significant (total indirect effect $=0.28,95 \%$ CI $0.13-0.54, P<0.001)$.

\section{The relationship between sleep, $\mathrm{VI}$, and emotional problems}

The predictive model of problematic behavior was significant in each case, explaining $32 \%, 31 \%, 61 \%$, and $61 \%(P<0.001$ for each) of the variance in internalizing behaviors, externalizing behaviors, anxiety, and depression respectively. VI at least partially mediated the impact of sleep disturbance on each behavior. The effect of sleep disturbance on behavior remained significant for internalizing behaviors and anxiety after the addition of VI to the model; however, strong mediation was shown for externalizing behaviors and depression scores.

\section{Total internalizing problems}

The results from the internalizing behavior analysis confirmed a partial mediation model (Figure 2A). That is, the

\section{A}
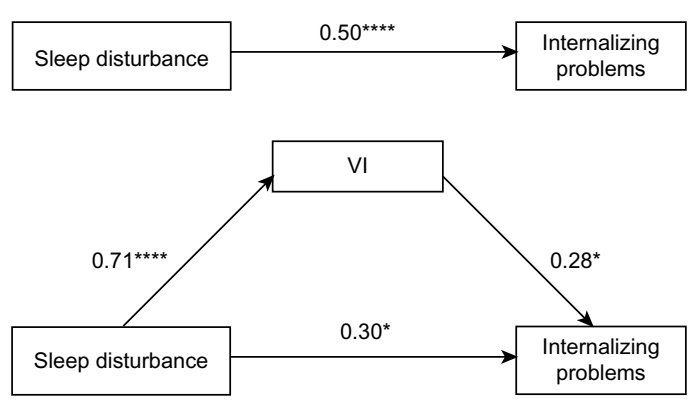

B
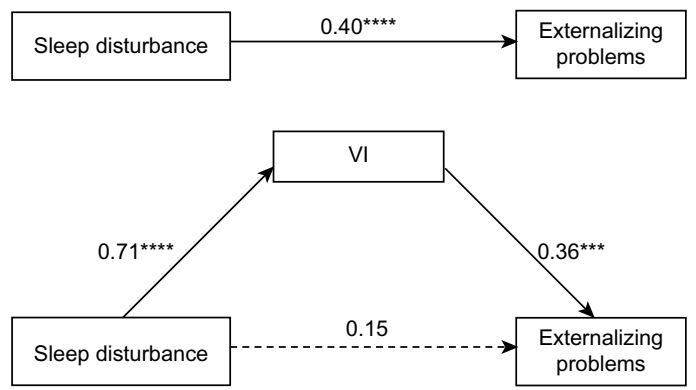

C
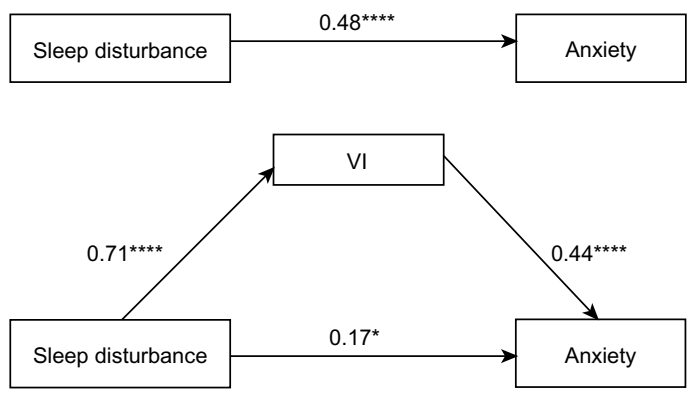

D
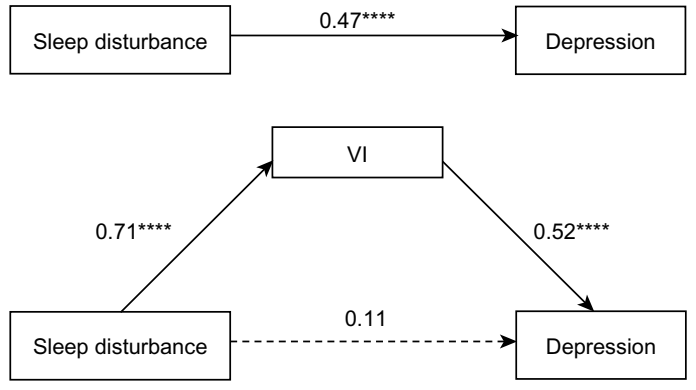

Figure 2 The effects of sleep disturbance, and mediation by reported resiliency on: (A) total internalizing problems; (B) externalizing problems; (C) anxiety symptoms; and (D) depression symptoms.

Notes: For each panel, the upper box is the association between degree of overall sleep disturbance and the behavioral variable, while the lower panel is the association after resiliency scores were entered into the model as a mediating variable. All numbers represent unstandardized coefficients. Solid lines indicate significant and dashed lines non-significant relationships. $* P<0.05$, $* * * P<0.005$, and $* * * * P<0.001$.

Abbreviation: $\mathrm{VI}$, vulnerability index. 
total effect of sleep disturbance on internalizing behavior ( $b=0.50, P<0.001)$ decreased with the inclusion of VI into the model $($ direct effect $=0.30, P<0.05)$. The total indirect effect of sleep disturbance through VI on internalizing behavior was significant (point estimate $=0.20,95 \%$ CI $0.05-0.47, P<0.05)$.

\section{Total externalizing problems}

The results from the externalizing behavior analysis revealed full mediation (Figure 2B). The total effect of sleep disturbance on externalizing behavior $(b=0.40, P<0.001)$ decreased with the inclusion of VI into the model (direct effect $=0.15, P>0.05$ ). The total indirect effect of sleep disturbance through VI on externalizing behavior was significant (point estimate $=0.26,95 \%$ CI $0.10-0.57, P<0.005$ ).

\section{Anxiety}

The results from the anxiety analysis revealed partial mediation (Figure 2C). The total effect of sleep disturbance on reported anxiety $(b=0.48, P<0.001)$ decreased with the inclusion of VI scores into the model (direct effect $=0.17$, $P<0.05$ ), and this change was statistically significant (total indirect effect $=0.31,95 \%$ CI $0.12-0.62, P<0.001)$.

\section{Depression}

The results from the depression analysis revealed full mediation (Figure 2D). The total effect of sleep disturbance on reported depression ( $b=0.47, P<0.001)$ decreased with the inclusion of VI scores into the model (direct effect $=0.11$, $P>0.05$ ), and this change was statistically significant (total indirect effect $=0.36,95 \%$ CI $0.15-0.66, P<0.001)$.

\section{Discussion}

The results of this study support the idea that strong associations exist between sleep problems and resiliency in children and adolescents, with sleep problems found to be predictive of resiliency scores. This is the first study to delineate the relationship between sleep and resilience, and to suggest how this relationship might relate to the development of problematic behavior in this age group. The results of the present study offer novel insights into the nature of resilience in children and adolescents, and can also be taken as support for recent works published in the area of pediatric sleep and psychopathology which have noted sleep problems as prodromal to anxiety problems. ${ }^{1}$ Interpreted through the lens of the present study, reduced sleep quality appears to result in loss of resilience (or increased vulnerability to a perceived lack of resources and/or emotional recovery), thus predisposing or precipitating behavioral and emotional problems.

It might be questioned as to why sleep should be related to the ability of the individual to adapt to negative environmental influences. One possible answer is that an increased rate of neuronal development in the brain of the resilient individual shields them from damage caused by environmental stressors, thereby helping the resilient individual to avoid psychopathology. ${ }^{14}$ Although not assessed in this study, if it is an increased capacity for neural plasticity which shields the resilient individual from the adverse effects of stressors, then the relationship between sleep and resilience becomes intuitive, as any factor which interferes with the brain's ability for plasticity potentially impacts the individual's level of resilience. It is said that sleep "enhances neuronal plasticity while sleep loss reduces it". ${ }^{39}$ The relationship between sleep and resilience could therefore be explained in terms of the synaptic homeostasis hypothesis in which synaptic connections are modulated during deep sleep stages to a sustainable baseline energy level through the downscaling of synaptic strength via low frequency, high amplitude cortical oscillations (ie, synchronized neural firing). ${ }^{40}$ This maintains neural plasticity for new environments, leaves physical space and neural energy for adaptations to new situations, and thus maintains the individual's capacity for learning and memory. ${ }^{41}$ Learning and memory have a logical link to resilience, as resilience as adaptation implies learning, and sleep has been consistently found to be important for the consolidation of new memories and, therefore, for learning skills necessary to adapt to a given environment. ${ }^{42}$ It could be expected that an individual with a greater capacity for neuroplasticity would have a better opportunity to learn adaptive strategies, and therefore to be more resilient in relation to stressful life events. Behaviorally, this was suggested in the results of the present study, in which a sense of mastery and sense of relatedness were found to be negatively related to sleep problems. Both of these variables relate to skill mastery (either general or social) and thus may be taken to suggest that the role of sleep in learning and memory is an active factor in determining the individual's level of resilience.

It may be interesting and worthwhile to consider whether resiliency has an influence on sleep in much the same manner as sleep has been suggested here to impact levels of resiliency. Evidence for this position comes from studies which note that stress impairs sleep quality, ${ }^{1,43}$ and that stressful events can have far-ranging impacts on sleep. ${ }^{43,44}$ These studies rest on the assumption that sleep and stress are opponent processes. ${ }^{2,3}$ The results of the present study take the position 
that sleep loss can reduce individual resiliency. This does not necessarily imply that all cases of sleeplessness will eventually manifest in lack of resiliency and psychopathology, but it does suggest that sleep problems may be a contributor to such outcomes. Indeed, it is important to remember that resiliency is a multi-level or systemic factor. ${ }^{14}$ While sleep loss may contribute to lack of resilience, there may be several other factors at play for any individual (such as level of social support and prior learning of coping strategies) which might bolster them against negative consequences. ${ }^{45} \mathrm{~A}$ pattern may be evident whereby higher quality sleep leads to greater resilience on a day-to-day level; however, if stressors do impact the individual beyond the protective point of their natural resilience and social supports, for example, it is likely that loss of sleep would lead to reduced resilience and thus commence a pattern of increasing risk of psychopathology.

The findings of the present study have particular relevance in the context of current research on resiliency. There are, at present, a number of studies and trials seeking to teach resiliency skills to both children ${ }^{46-49}$ and adults. ${ }^{50-53}$ These studies have largely reported success in increasing resilience and decreasing psychopathology; however, there have also been reports of variance in effectiveness and small effect sizes. ${ }^{48,49}$ None of these studies have considered the specific role of sleep as a mechanism in promoting resilience. In the light of the findings of the present research, it might be considered whether an effective resilience intervention should include components related to promoting sleep quality (for instance, the establishment of positive sleep associations or good sleep hygiene), or at the very least, on obviating sleep problems. These results also suggest that sleep factors, such as sleep hygiene, and medical conditions which can interfere with attaining restful sleep, such as obstructive sleep apnea, should be controlled for in any study which attempts to delineate individual levels of resiliency.

The present study had adequate sample size and statistical power to support the analyses (observed statistical power was $\geq 0.85$ for all levels of $P$ ). There are, however, certain limitations which should be considered in interpreting the study. Foremost of these is the fact that, despite suggesting neuroplasticity as an underlying mechanism for the relationship between sleep and resilience, no direct measures of this were taken. Neuroplasticity is thus proposed as a theoretical explanatory tool based on published literature which has noted a role of sleep in promoting brain plasticity, ${ }^{39}$ and thus in promoting resilience. ${ }^{14}$ Future studies could demonstrate greater evidence for a relationship between sleep and resiliency through instituting a protocol such as that followed by
Taki et al, ${ }^{41}$ who used voxel-based morphometry to determine the effects of restricted sleep schedules on the volume of grey matter in the bilateral hippocampal body of healthy children. Such a protocol, targeted at the areas of the brain known to be associated with resiliency ${ }^{21,23}$ would allow for a more fine grained analysis of the neural bases of resilience and the effects of sleep restriction/deprivation thereon. The results from this study suggest the reported associations are present from middle childhood to late adolescence. However, in addition to work focusing on understanding the underlying mechanisms of the effects shown, longitudinal work aimed at characterizing developmental changes in the magnitude of the reported associations over time, and the changes in practical implications, is needed. ${ }^{4}$ This study also relies on self-reported and parentally-reported measures. Objectively defined sleep, such as by using overnight polysomnography, will be an important extension of the findings reported. This will allow further delineation of the sleep-related neural mechanisms for the effects presented. Indeed, using polysomnography, Brand et al have shown that adolescents with higher mental toughness, a concept with some overlap with resilience, show more efficient sleep and less daytime tiredness than those with low mental toughness scores. ${ }^{19}$ Small differences in sleep stage parameters were also observed between groups, and future studies can determine whether such features of sleep are also associated with resilience, and subsequent daytime functioning.

The present study is the first to indicate a relationship between sleep and resilience in healthy children and adolescents. Further to this, the present study is the first to suggest a manner in which this relationship may influence the development of psychopathology in the individual. This finding has theoretical implications for understanding both the role of sleep and the mechanisms underlying resilience, as well as practical implications for the fields of clinical and positive psychology, insofar as it demonstrates that there may be physiological requirements (ie, quality sleep) which must be met before resilience can be enhanced in the individual to any significant degree. This is of relevance to any practitioner seeking to alleviate symptoms of psychopathology, and of particular interest due to the large number of current ventures into teaching resilience as part of psychology-related programs.

\section{Disclosure}

The authors report no conflicts of interest in this work.

\section{References}

1. Leahy E, Gradisar M. Dismantling the bidirectional relationship between paediatric sleep and anxiety. Clin Psychol. 2012;16:44-56. 
2. Dahl RE, Harvey AG. Sleep in children and adolescents with behavioural and emotional disorders. Sleep Med Clin. 2007;2:501-511.

3. Dahl RE. The regulation of sleep and arousal: development and psychopathology. Dev Psychopath. 1996;8:3-27.

4. Gregory AM, Sadeh A. Sleep, emotional and behavioral difficulties in children and adolescents. Sleep Med Rev. 2012;16:129-136.

5. Baglioni C, Battagliese G, Feige B, et al. Insomnia as a predictor of depression: a meta-analytic evaluation of longitudinal epidemiological studies. J Affect Dis. 2011;135:10-19.

6. Lucassen PJ, Meerlo P, Naylor AS, et al. Regulation of adult neurogenesis by stress, sleep disruption, exercise and inflammation: implications for depression and antidepressant action. Euro Neuropsychopharmacol. 2010;20:1-17.

7. Meerlo P, Mistlberger RE, Jacobs BL, Heller CH, McGinty D. New neurons in the adult brain: the role of sleep and consequences of sleep loss. Sleep Med Rev. 2009;13:187-194.

8. Talbot LS, McGlinchey EL, Kaplan KA, Dahl RE, Harvey AG. Sleep deprivation in adolescents and adults: changes in affect. Emotion. 2010;10:831-841.

9. Sadeh A. Consequences of sleep loss or sleep disruption in children. Sleep Med Clin. 2007;2:513-520.

10. Chorney DB, Detweiler MF, Morris TL, Kuhn BR. The interplay of sleep disturbance, anxiety, and depression in children. $J$ Pediatr Psychol. 2008;33:339-348.

11. Kobayashi I, Boarts JM, Delahanty DL. Polysomnographically measured sleep abnormalities in PTSD: a meta-analytic review. Psychophysiology. 2007;44(4):660-669.

12. Brown TH, Mellman TA, Alfano CA, Weems CF. Sleep fears, sleep disturbance, and PTSD symptoms in minority youth exposed to Hurricane Katrina. J Trauma Stress. 2011;24:575-580.

13. Herrman H, Stewart DE, Diaz-Granados N, Berger EL, Jackson B, Yuen T. What is resilience? Can J Psychiatry. 2011;56:258-265.

14. Cicchetti D. Resilience under conditions of extreme stress: a multilevel perspective. World Psychiatry. 2010;9:145-154.

15. Sapienza JK, Masten AS. Understanding and promoting resilience in children and youth. Curr Opin Psychiatry. 2011;24:267-273.

16. Hunter $\mathrm{C}$. Is resilience still a useful concept when working with children and young people? Paper no 2. 2012. Available from: http://www.aifs. gov.au/cfca/pubs/papers/a141718/index.html. Accessed September 6, 2013.

17. Kim DH, Yoo IY. Factors associated with depression and resilience in asthmatic children. J Asthma. 2007;44:423-427.

18. Southwick SM, Vythilingam M, Charney DS. The psychobiology of depression and resilience to stress: Implications for prevention and treatment. Annu Rev Clin Psychol. 2005;1:255-291.

19. Brand S, Gerber M, Kalak N, et al. Adolescents with greater mental toughness show higher sleep efficiency, more deep sleep and fewer awakenings after sleep onset. J Adolesc Health. Epub August 30, 2013.

20. Lemola S, Räikkönen K, Scheier MF, et al. Sleep quantity, quality and optimism in children. J Sleep Res. 2011;20:12-20.

21. McCrory E, De Brito SA, Viding E. Research review: the neurobiology and genetics of maltreatment and adversity. J Child Psychol Psychiatry. 2010;51:1079-1095.

22. Beebe DW, Gozal D. Obstructive sleep apnoea and the pre-frontal cortex: towards a comprehensive model linking nocturnal upper airway obstruction to daytime cognitive and behavioural deficits. J Sleep Res. 2002;11:1-16.

23. Feder A, Nestler EJ, Charney DS. Psychobiology and molecular genetics of resilience. Nat Rev Neurosci. 2009;10:446-457.

24. Mignot E, Taheri S, Nashino S. Sleeping with the hypothalamus: emerging therapeutic targets for sleep disorders. Nat Neurosci. 2002;5: 1071-1075.

25. Calvo JM, Fernández-Guardiola A. Phasic activity of the basolateral amygdala, cingulate gyrus, and hippocampus during REM sleep in the cat. Sleep. 1984;7:202-210.
26. Prince-Embury S. Psychometric properties of the resiliency scales for children and adolescents and use for youth with psychiatric disorders. J Psychoeduc Assess. 2010;28:291-302.

27. Kumar G, Steer RA, Gulab NA. Profiles of personal resiliency in child and adolescent psychiatric inpatients. J Psychoeduc Assess. 2010;28(4): 315-325.

28. Prince-Embury S, Courville T. Comparison of one-, two- and threefactor models of personal resiliency using the resiliency scales for children and adolescents. Can J School Psychol. 2008;23:11-25.

29. Prince-Embury S, Steer RA. Profiles of personal resiliency for normative and clinical samples of youth assessed by the resiliency scales for children and adolescents. J Psychoeduc Assess. 2010;28:303-314.

30. Prince-Embury S. The resiliency scales for children and adolescents, psychological symptoms, and clinical status in adolescents. Can $J$ School Psychol. 2008;23:41-56.

31. Bruni O, Ottaviano S, Guidetti V, et al. The sleep disturbance scale for children (SDSC): construction and validation of an instrument to evaluate sleep disturbances in childhood and adolescence. J Sleep Res. 1996;5:251-261.

32. Achenbach TM, Rescorla LA. Manual for the ASEBA School-Age Forms and Profiles. Burlington: University of Vermont, Research Centre for Children, Youth, and Families; 2001.

33. Ang RP, Rescorla LA, Achenbach TM, Ooi YP, Fung DSS, Woo B. Examining the criterion validity of CBCL and TRF problem scales and items in a large Singapore sample. Child Psychiatry Hum Dev. 2012;43: $70-86$.

34. Beck JS, Beck AT, Jolly J. Manual for the Beck Youth Inventories of Emotional and Social Impairment. San Antonio, TX: Psychological Corp; 2001.

35. Steer RA, Kumar G, Beck JS, Beck AT. Evidence for the construct validities of the Beck Youth Inventories with child psychiatric outpatients. Psychol Rep. 2001;89:559-565.

36. Preacher KJ, Hayes AF. Asymptotic and resampling strategies for assessing and comparing indirect effects in multiple mediator models. Behav Res Methods. 2008;40:879-891.

37. MacKinnon DP, Lockwood CM, Hoffman JM, West SG, Sheets V. A comparison of methods to test mediation and other intervening variable effects. Psychol Methods. 2002;7:83-104.

38. Preacher KJ, Hayes AF. SPSS and SAS procedures for estimating indirect effects in simple mediation models. Behav Res Methods Instrum Comput. 2004;36:717-731.

39. Jan JE, Reiter RJ, Bax MCO, Ribary U, Freeman RD, Wasdell MB. Long-term sleep disturbance in children: a cause of neuronal loss. Eur J Paediatr Neurol. 2010;14:380-390.

40. Tononi G, Cirelli C. Sleep function and synaptic homeostasis. Sleep Med Rev. 2006;10:49-62.

41. Taki Y, Hashizume H, Thyreau B, et al. Sleep duration during weekdays affects hippocampal gray matter volume in healthy children. Neuroimage. 2012;60:471-475.

42. Diekelmann S, Born J. The memory function of sleep. Nat Rev Neurosci. 2010;11(2):114-126.

43. Greenfield EA, Lee C L, Friedman EL, Springer KW. Childhood abuse as a risk factor for sleep problems in adulthood: Evidence from a US National study. Ann Behav Med. 2011;42:245-256.

44. Chambers E, Belicki K. Using sleep dysfunction to explore the nature of resilience in adult survivors of childhood abuse or trauma. Child Abuse Neglect. 1998;22:753-758.

45. Afifi TO, MacMillan HL. Resilience following child maltreatment: a review of protective factors. Can J Psychiatry. 2012;56:266-272.

46. Lester P, Saltzman WR, Woodward K, et al. Evaluation of a familycentered prevention intervention for military children and families facing wartime deployments. Am J Pub Health. 2012;102:48-54.

47. Borden LA, Schultz TR, Herman KC, Brooks CM. The incredible years parent training program: Promoting resilience through evidencebased prevention groups. Group Dyn Theory Res Pract. 2010;14: 230-241. 
48. Seligman MEP, Ernst RM, Gillham J, Reivich K, Linkins M. Positive education: positive psychology and classroom interventions. Oxford Rev Educ. 2009;35:293-311.

49. Gillham J, Reivich K, Freres DR, et al. School-based prevention of depressive symptoms: A randomized controlled study of the effectiveness and specificity of the Penn resiliency program. J Consult Clin Psychol. 2007;75:9-19.

50. Foran HM, Adler AB, McGurk D, Bliese P. Soldiers' perceptions of resilience training and postdeployment adjustment: validation of a measure of resilience training content and training process. Psychol Serv. 2012;9:390-403
51. Howe A, Smajdor A, Stöckl A. Towards an understanding of resilience and its relevance to medical training. Med Educ. 2012;46:349-356.

52. Reivich KJ, Seligman MEP, McBride S. Master resilience training in the US Army. Am Psychol. 2011;66:25-34.

53. Varker T, Devilly GJ. An analogue trial of inoculation/resilience training for emergency services personnel: proof of concept. J Anxiety Disord. 2012;26:696-701

\section{Publish your work in this journal}

Nature and Science of Sleep is an international, peer-reviewed, open access journal covering all aspects of sleep science and sleep medicine, including the neurophysiology and functions of sleep, the genetics of sleep, sleep and society, biological rhythms, dreaming, sleep disorders and therapy, and strategies to optimize healthy sleep. The journal welcomes

\section{Dovepress}

original research, clinical \& epidemiological studies, reviews \& evaluations, case reports and extended reports. The manuscript management system is completely online and includes a very quick and fair peerreview system, which is all easy to use. Visit http://www.dovepress.com/ testimonials.php to read real quotes from published authors.

Submit your manuscript here: http://www.dovepress.com/nature-and-science-of-sleep-journal 